\title{
Laparoscopic partial splenectomy by using two techniques in goats
}

\section{Z. J. Malik ${ }^{1}$ and M. J. Eesa ${ }^{\circledR 2}$}

${ }^{1}$ Student MSc, Surgery, ${ }^{2}$ Department of Surgery and Obstetrics, College of Veterinary Medicine,

Baghdad University, Iraq.

E-mail: _mohammad2006_eesa@yahoo.com

Accepted: 15/06/2014

Summary

The aim of this study is to evaluate the laparoscopic partial splenectomy, using horizontal interrupted mattress suture and electro- cautery techniques in goats. Sixteenth adult goats were divided into two main equal groups (A and B). Each group was additionally divided into two equal subgroups, according to follow up on $15^{\text {th }}$ and $30^{\text {th }}$ days postoperatively for histopathology examination.All operations were performed under general anesthesia. Physical and clinical examination were measured pre-operatively and $1^{\text {st }}$ to $7^{\text {th }}$ days postoperative. The results revealed that the two techniques of both groups were performed successfully and the operation time in group A was $86.125 \pm 20 \mathrm{~min}$., which was longer than that in group B $62.375 \pm 10 \mathrm{~min}$. There were significant $(\mathrm{P}<0.05)$ differences in the physical parameters in all the experimental goats. All animals gradually returned to the normal solid food intake and activity, defecation and urination after $72 \mathrm{hrs}$ postoperative. Laparoscopic gross pathological changes revealed adhesions between spleen, rumen, and abdominal wall which were more severe in group A as compared with group B. Histopathology examination showed that both groups were associated with collagen and fibrous tissue formation similar to capsule surrounding the site of the incision, which was more in group B than in group A, and the latter group was infiltrated with more inflammatory cells. Also group B had more lymphocyte aggregation around the central artery, in addition to that there was thickness of capsule and mature granulation tissue, but in group A there was edema, congested red pulp and immature granulation tissue.

Keywords: Partial splenectomy, Laparoscope, Electro cautery, Goats.

\section{Introduction}

Spleen in goats is considered as a reservoir of blood cells which can be mobilized by splenic contraction (1). Partial splenectomy was used instead of total splenectomy to reserve splenic function (2). In the laparoscopic spleen-preserving surgery, the complications include hemorrhage, visceral injury, infection, splenic vein thrombosis (3). Splenectomy was first described in 1910 by Sutherland but laparoscopic splenectomy was first described in 1991 by Delaitre and Maignien (4). After the dawn of the laparoscopic era, it was not very long until Delaitre (5), reported the first laparoscopic splenectomy. Shortly after the first publications of laparoscopic splenectomies, experimental and then clinical laparoscopic partial resections of the spleen were reported (6). Laparoscopic partial splenectomy was performed successfully in all the experimental dogs without any obvious complication (2). Open procedure is used only for excessively enlarged spleen (5). Laparoscopic partial splenectomy was performed successfully in all the experimental dogs without any obvious complication, used adrenaline with titanium clips, thermo-cautery device, compared with the open partial splenectomy (2). The aim of this study was to evaluate the laparoscopic partial splenectomy using horizontal interrupted suture and electro-cautery techniques laproscopically in goats.

\section{Materials and Methods}

Sixteenth adult healthy goats were used. The animals were kept under similar conditions of management and feeding. They were housed in farm animals, College of Veterinary Medicine, Baghdad University. The animals were made fast to 36 hours for feeding and 12 hours for water pre-operation. The ventral abdominal area from xiphoid cartilage in to pubis and laterally into the left flank as far as possible was prepared aseptically. The operations were done under general anesthesia by using xylazine hydrochloride $(0.2 \mathrm{mg} / \mathrm{kg}$ B.W) and ketamine hydrochloride $(4 \mathrm{mg} / \mathrm{kg}$ 
B.W) intramuscularly and inserted endotracheal tube. The anesthetized goat was laid on right lateral recumbence, the head was risen and the body slightly changed in to the left lateral position (Trendelenburg position). The animal underwent laparoscopic partial splenectomy after inserting four ports (Fig. 1) and using pneumoperitoneum $(10 \mathrm{~mm} \mathrm{Hg})$.

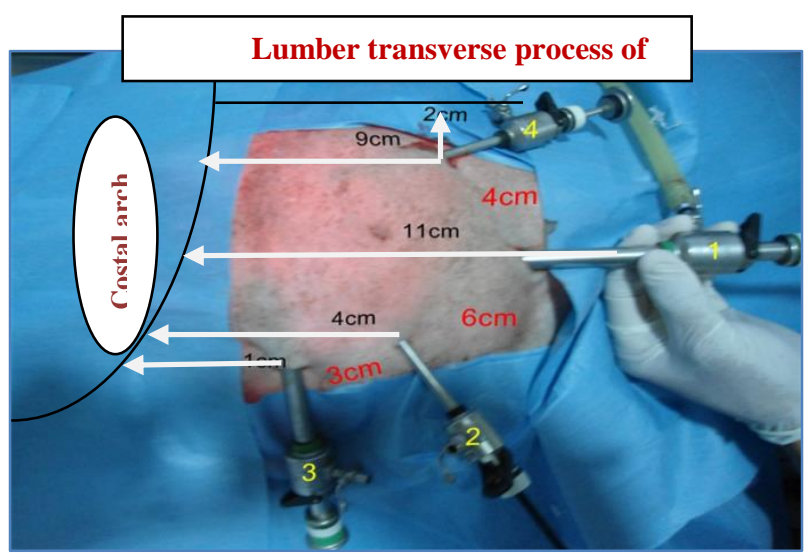

Figure, 1: The ports site for telescope and the other laparoscpic instruments, $(10 \mathrm{~mm})$ for telescope $(1),(5 \mathrm{~mm})$ for grasper $(2),(10 \mathrm{~mm})$ for needle holder or electrocautery (3) and (10mm) for scissor (4).

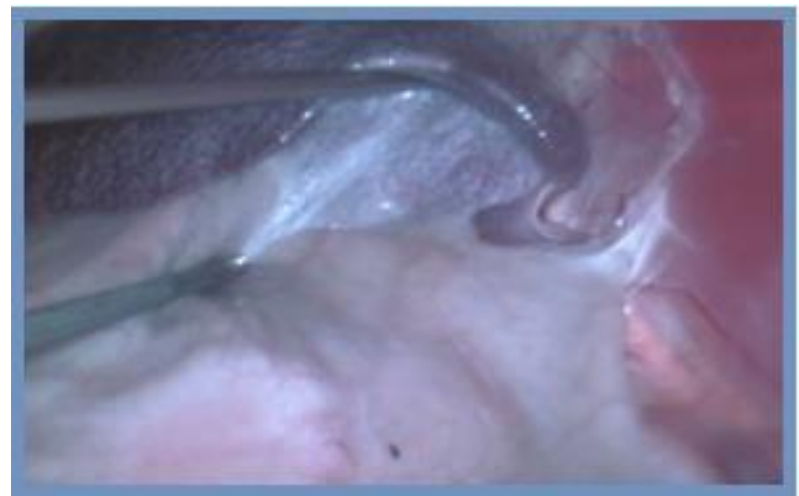

Figure, 2: The dissection between spleen and dorsal side of rumen.

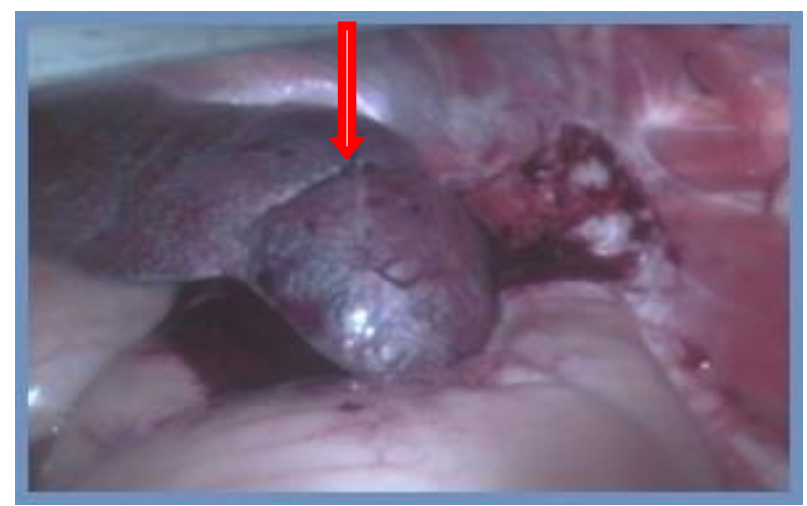

Figure, 3: The interrupted horizontal mattress suture was applied around the splenic resected part (red arrow) in group A

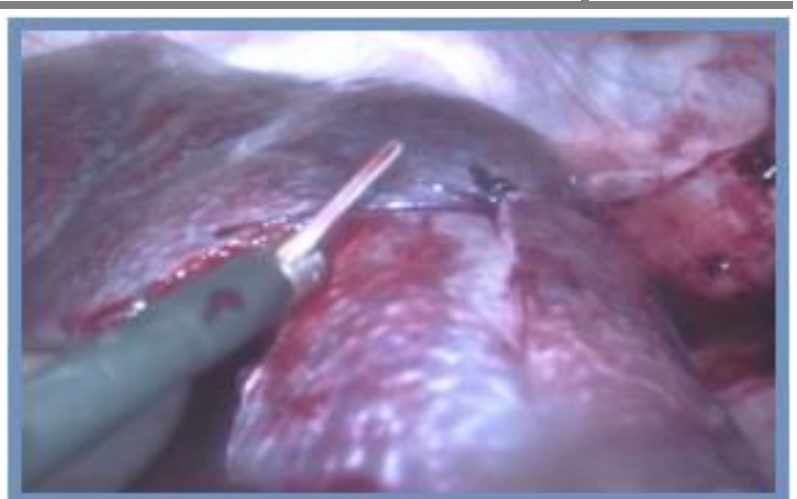

Figure, 4: Cutting part of spleen by laparoscopic scissor in group $\mathbf{A}$.

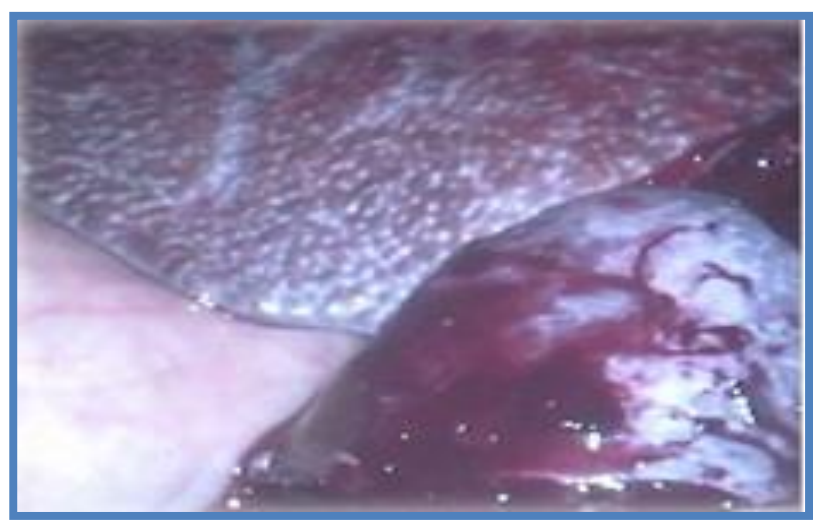

Figure, 5: Excised part of spleen near original spleen.

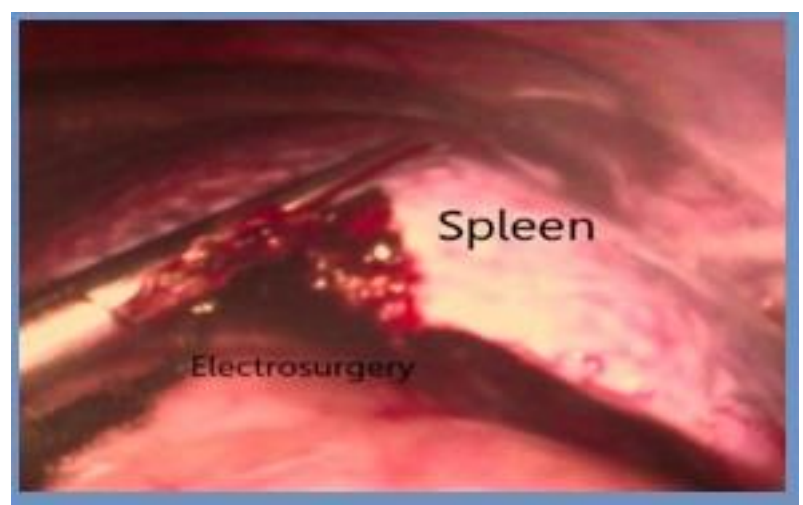

Figure, 6: Photograph of group B electro-surgery used to cutting through splenic parenchyma (arrow).

They were divided into two main groups: Group, A (Horizontal interrupted mattress suture): In which laparoscopic partial splenectomy was performed after the resected area was surrounded by horizontal interrupted mattress suture intracorporeally using polygalactine 910 (polygalactin 910, size 0.1, Switzerland) and cutting by successor (Fig. 2, 3 and 4) then the resected part (Fig., 5) was removed through dilation of port. In group, B (Electro-cautery): laparoscopic partial splenectomy was done using monopolar electro-cautary (coagulant and cutting 
technique), same as in group A but instead of suture used monopolar electrocautery (Fig. 6) for resected and stop bleeding. The animals of each group were subdivided into two equal subgroups, 4 animals for each depended on follow up at 15 and 30 days post-operation for histopathology examination.

\section{Results and Discussion}

The clinical observations of experimental animals after operation were appeared active; return to normal feeding after one day and there was slight swelling at the site of incision which disappeared at 5 days post operations. This might be due to small blunt incision with slight tissue trauma. This coincides with (7). There were significant $(\mathrm{P}<0.05)$ differences in the physical parameters in all the experimental goats. This fact revealed that, this laparoscopic partial splenectomy cause mild changes on the physical condition of animals. The macroscopic findings show adhesion between spleen, rumen and abdominal wall. The percentage of this adhesion was more in group A compared with group B (Fig. 7 and 8). This might be rough manipulation during application of horizontal mattress suture. The mean time for the operation period was $86.125 \pm 20$ min. in group A, while in group B was $62.375 \pm 10 \mathrm{~min}$. This fact indicated that the application of horizontal interrupted mattress suture consumed longer time; intracorporeal suture was needed high skill to donestitches.

At $15^{\text {th }}$ days postoperative in group A: The histopathology examination showed congested blood vessels with fibrin deposition in incision area, in other section irregular collagen fiber and congested blood vessels with inflammatory cells in there lumen (Fig. 9). This fibrin network deposition occurrence may be due to the body consideration of the suturing foreign body. Inflammatory cells may be due to decrease of blood supply in adjacent area of incision as a result of injury. The same result was concluded by (2 and 8 ). Sever congestion of red pulp, necrosis of lymphocyte and inflammatory cells infiltration), this might be due to the inflammatory cells release enzymes to destruction tissues, therefore the increased damaging tissues caused more increased release of lysosomes enzyme and appeared the debris. This note was mentioned by ( 9 and 10).

In other sections, the spleen showed increase thickness of capsular region, with granulation tissue (Fig. 10). This may be due to the beginning of repair stage, this phenomena was described by (11), also it might be the effect of suture materials in adjacent area, this agrees with (12 and 13).

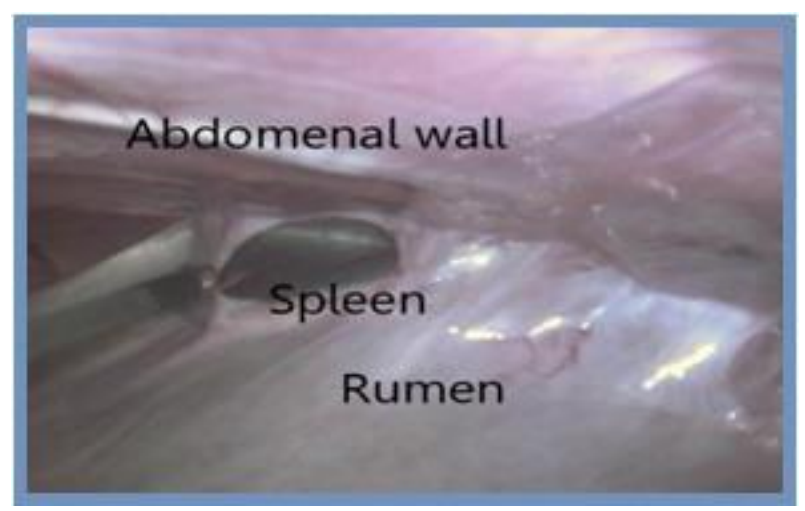

Figure, 7: The adhesion between spleen, abdominal wall and rumen at 30 days in goat group $A$.

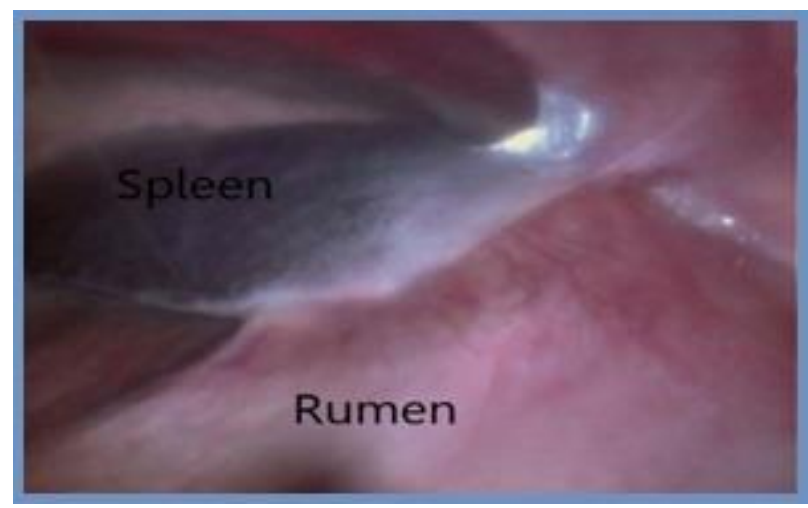

Figure, 8: The adhesion between site of partial splenectomy and at 30 days rumen in goat group $B$.

At $30^{\text {th }}$ day postoperative, the histopathology examination showed necrosis of lymphocytes, moderate fibrous connective tissue, monocular cells infiltration and congestion of red pulp. This may be due to fibroblastic phase occurrence and made ground substance due to secreted protein polysaccharides and glycoprotein. This coincides with other researcher's (11 and 14). In other sections marked mature fibrous connective tissue proliferation extended to the incision area and surrounded congested blood vessels with aggregation of monocular cell. The formation of fibrous tissue may be mature period of healing. In other section fibrous 
connective tissue, aggregation of lymphocyte and edema in the incision area. However, small white and red pulp started formation in the necrotic area in the incision with congestion of blood vessels (Fig. 11). Small

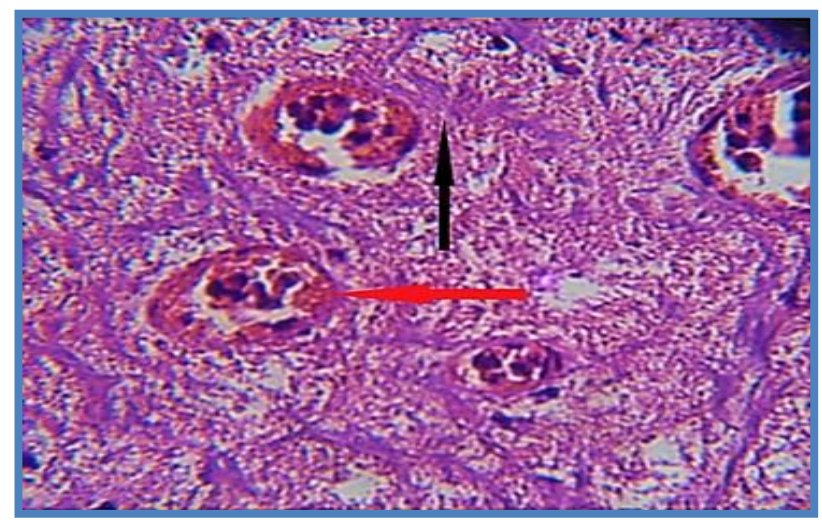

Figure, 9: Irregular collagen fiber (black arrow) and congested blood vessels with neutrophil in there lumen (red arrow) at $15^{\text {th }}$ day in goat of group $\mathrm{A}(\mathrm{H}$ and $\mathrm{E}$ stain $40 \mathrm{X})$.

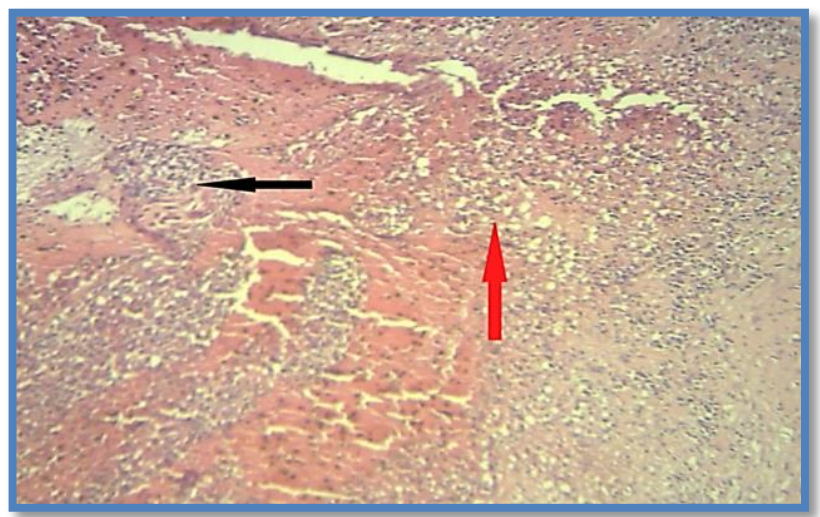

Figure, 11: Micrograph of goat group A congested blood vessels (black arrow), initiated white and red pulp in incision area (red arrow) at $30^{\text {th }}$ day postoperative ( $\mathrm{H}$ and $\left.\mathrm{E} 10 \mathrm{X}\right)$.

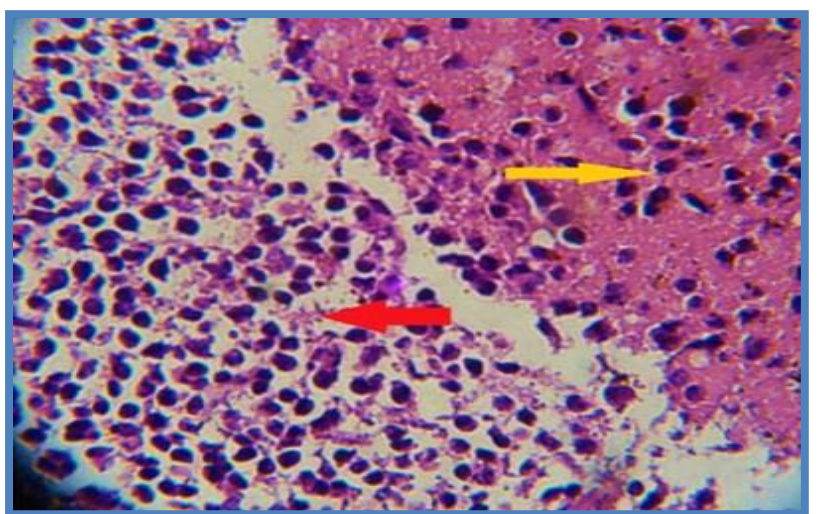

Figure, 13: Micrograph of goat group B mononucular cells infiltration in the incision area (red arrow) and fibrin deposition (yellow arrow) at $15^{\text {th }}$ day postoperative ( $\mathrm{H}$ and $\left.\mathrm{E} 10 \mathrm{X}\right)$.

At $15^{\text {th }}$ day postoperative in group B: The histopathology examination showed that congestion of red pulp in area adjacent to incision, however in other sections the lesion white pulp started formation (regeneration), this leads to suggestion of starting the mitosis of this tissue, this phenomena was mentioned by (11) and this lead to result that the spleen have capable to regeneration.

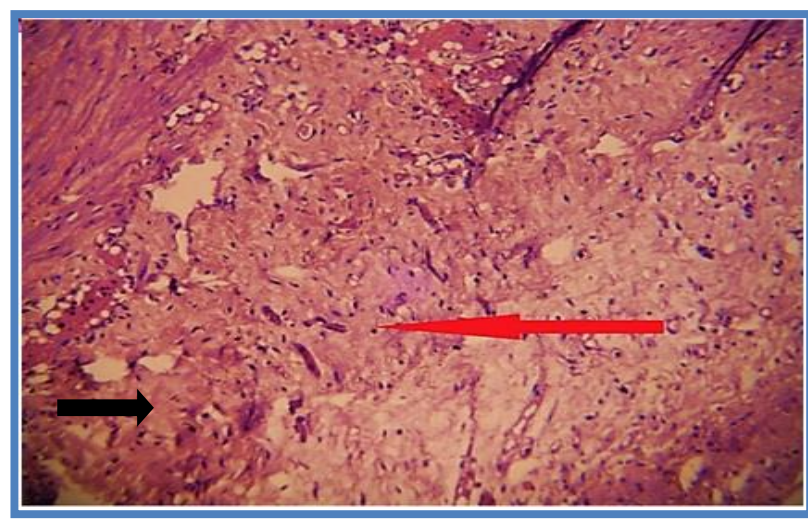

Figure, 10: Micrograph of goat group A shows increase thickness of capsular area (red arrow) granulation tissue (black arrow) at $15^{\text {th }}$ day postoperative ( $\mathrm{H}$ and $\mathrm{E} 10 \mathrm{X}$ ).

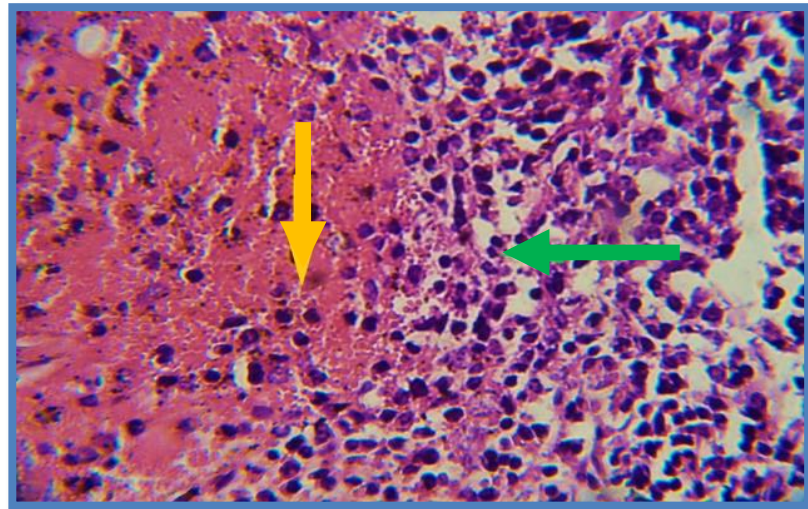

Figure, 12: Micrograph of goat group B inflammatory cells infiltration (green arrow) white and red pulp in the incision area initiated (yellow arrow) at $15^{\text {th }}$ day postoperative ( $\mathrm{H}$ and $\mathrm{E} 40 \mathrm{X}$ ).

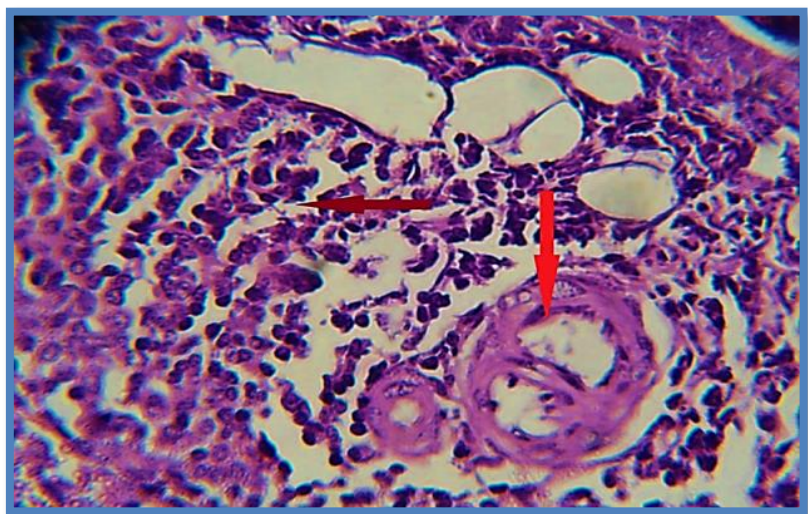

Figure, 14: Micrograph of goat group B mononucular cells infiltration (brown arrow) with aggregation of lymphocyte around blood vessel in the incision (red arrow) at $30^{\text {th }}$ day postoperative (H and $\mathrm{E} 40 \mathrm{X}$ ).

characterized by monocular cell infiltration and aggregation of lymphocyte (Fig. 12), also monocular cells infiltration with fibrin deposition (Fig. 13). At $30^{\text {th }}$ day postoperative, 
it showed the main lesion characterized by monocular cell infiltration with lymphocyte aggregation around blood vessels in the incision area (Fig. 14). This means beginning of healing of operative site (regeneration) this agrees with (14). The spleen showed mature granulation tissue characterized by congestion blood vessels with inflammatory cells in their lumen particularly lymphocyte in addition to regular collagen fiber produced by fibroblast. Other sections showed aggregation of lymphocytes around central artery (regeneration) in the incision (Fig. 15).

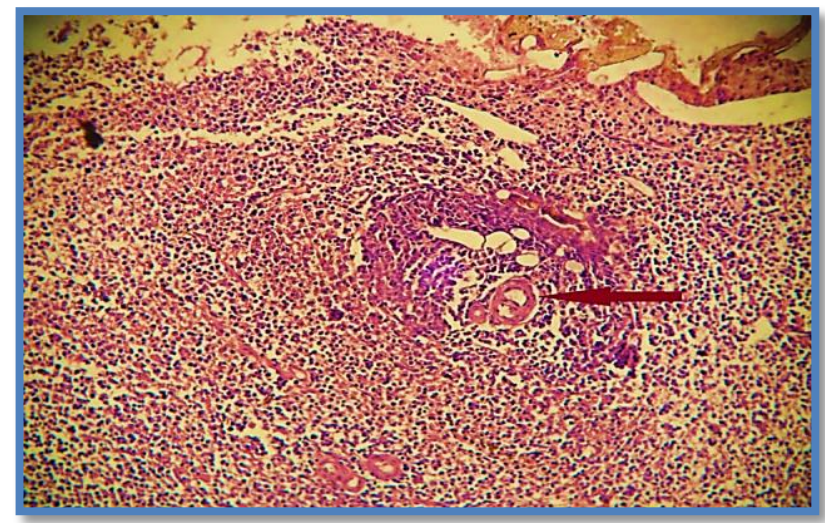

Figure, 15: Micrograph of goat group $B$ aggregation of lymphocytes around central artery in the incision area (brown arrow) at 30th day postoperative ( $\mathrm{H}$ and $\mathrm{E} 10 \mathrm{X})$.

The thickness of capsular region of the spleen may be due to proliferation of connective tissue, congested of blood vessels and infiltration of inflammatory cells, in addition to congestion in the red pulp together with lymphocyte infiltration. This may be due to collagen occurrence, this means that the inflammatory process in ending phase, because the presence of myofibroblasts in the wound site which indicated that the wound is in the mature phase, this result coincides with other authors like (15).

\section{References}

1. Abdalla, S. E. and Abdelatif, A. M. (2010). Physiological responses of goats (Capra hircus) to haemorrhage as influenced by splenectomy. American-Eurasian Journal of Scientific Research Faculty of Veterinary Medicine, University of Khartoum, Sudan; 5 (2): 76-87.

2. Al- Hasan, A. M. and Al- Heani, W. A. (2009). Laparoscopic partial splenectomy in dogs Mosul. Iraq. J. Ani. and Vet. Adv., 8(11): 2232-2240.

3. Lianxin, L.; Dalong, Y.; and Hongchi, J. (2011). Spleen preserving Surgery and related laparoscopic techniques, Updated Topics in Minimally Invasive Abdominal Surgery, Elgeidie, A. (Ed.), Pp: 953978,307, 773-774.

4. Nasr, W. I.; Collins, C. L. and Kelly, J. J. (2004). Feasibility of laparoscopic splenectomy in stable blunt trauma: A case series. J Trauma; 57:887-889.

5. Selman, U. and Orhan, A. (2005). Laparoscopic surgery of the spleen. Surg. Clin. N. Am. 85: 75-90.

6. Uranus, S.; Pfeifer, J.; Schauer, C. and Kronberger, L. et al. (1995). Laparoscopic partial splenic resection. Surg. Laparosc. Endosc., 5:133-136.

7. Theoret, C. L. (2004). Update on wound repair. Clin. Tech. in Equine Prac., 3(2): 110122.

8. Paulo, D. N.; Paulo, I.; Kalil, M.; Vargas, P. M.; Silva, A. L.; Baptista, J. F. and Guerra, A. J. (2006). Subtotal splenectomy preserving the lower pole in rats: Technical, morphological and functional aspects. Acta Cir. Bras., 21: 321- 327.

9. Fowler, D. (1993). Principle of wound healing. Harari, J. Surgical complication and wound healing in the small animal practice Saunders Company, Pp: 2-27.

10. Deodhar, A. K. and Rana , R. E. (1997). Surgical physiology of wound healing: areivew. J. Postgraduate Medicine JPGM., 43(2):52 -59.

11. Slater, B. J.; Chan, F. P.; Davis, K. and Dutta, S. (2010). Institutional experience with laparoscopic partial splenectomy for hereditary spherocytosis J. Pediatr. Surg. 45(8):1682-6.

12. Hess, J. L., McCurnin, D. M.; Riley M.G. and Koehler, K. J. (1981). Pilot study for comparison of chromic cat gut suture and mechanically applied staples anastomosis $\mathrm{J}$. Am.Anim. Hosp. Assoc., 17:409- 414.

13. Hanson, R. R.; Nixon, A. J.; Calderwood Mays, M. and Gronwall, R. (1988). Evaluation of three techniques for end to endanastomosis of small colon in horses. Am. J. Vet. Res. 49: 1613-1620. 
14. Fossum, T.W. (2007). Small Animal Surgery. $3^{\text {rd }}$ Edn. Mosby Inc.,China. Pp: 692704.

15. Eichler, M. J. and Carlson, M. A. (2006).
Modeling dermal granulation tissue with the linear fibroblast-populated collagen matrix: comparison with the round matrix model. J. derma. Sci., 41(2): 97-108.

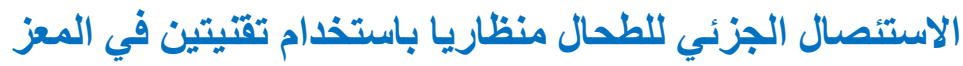

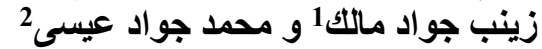 \\ 1 طالب ماجستير، 2 فرع الجر احة والتو مالتوليد، كلية الطب البيطري، جامعة بغداد، العر اق.}

E-mail: mohammad2006_eesa@yahoo.com

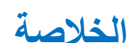

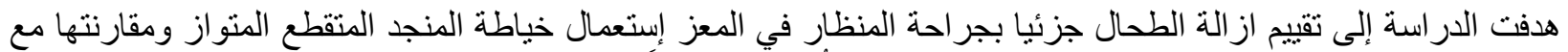

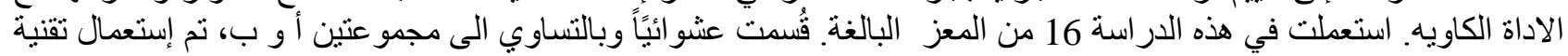

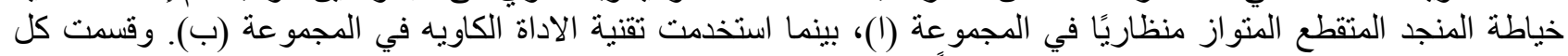

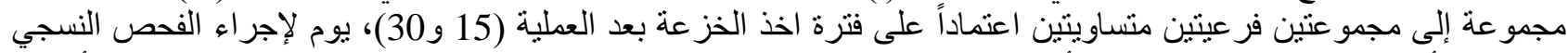

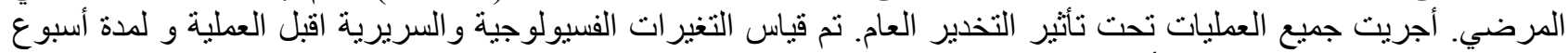

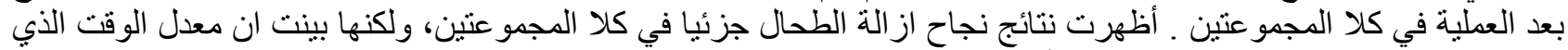

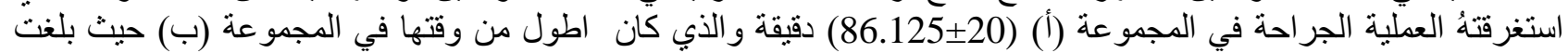

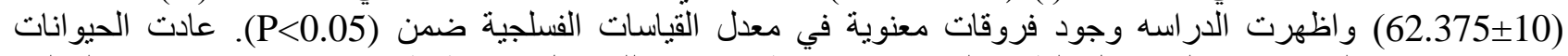

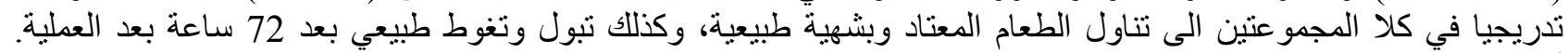

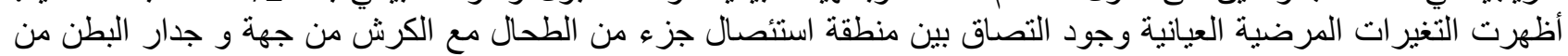

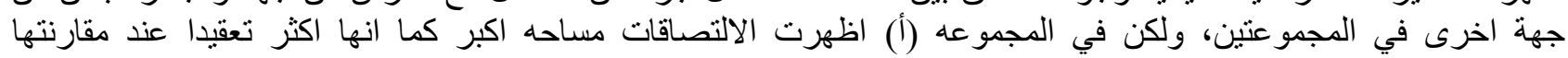

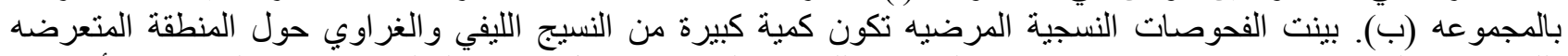

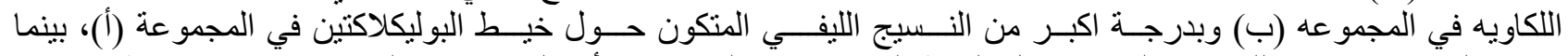

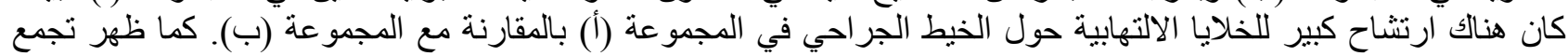

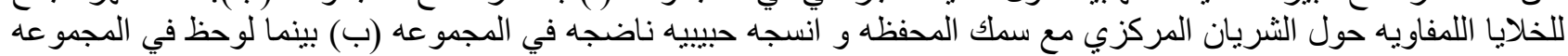

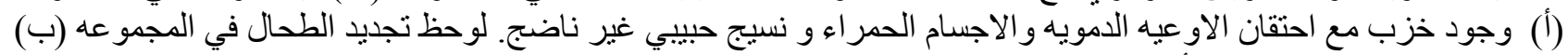

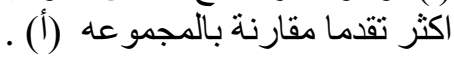
الكلمات المفتاحية: ازالة الطحال جزئيا، المنظار، الاداة الكاويه، المعز. 